\title{
Chinese Proverbs in American Verbal Culture
}

\author{
Ekaterina A. lakovleva \\ Olga V. Nikolaeva
}

Far Eastern Federal University. Vladivostok, Office D 720, bld. 20, Campus FEFU, Russky Island, Russia Email: iakovleva.ekaterina2015@yandex.ru

\section{Doi:10.5901/mjss.2016.v7n1s1p284}

\section{Abstract}

The paper deals with the question of Chinese proverb quotations in American mass and social media discourse. This is a specific aspect of a much broader issue of intercultural communication, that is how proverbs being both verbally and culturally unique enter entirely different society and eventually become the part of its verbal culture and communication. Despite significant research made in the field of language contacts, especially loanword phenomena, there are still apparently few works devoted to proverb borrowings. However, the evidence proves that foreign language proverbs freely and extensively circulate in many world languages. In this regard contemporary English, where their frequency as well as diversity has recently become remarkably conspicuous, deserves a special study. Numerous proverbs of other countries are not only quoted in the English-language communication, but also enter proverb corpora and dictionaries of English. It holds particularly true for the phenomenon of Chinese proverbs. The empirical data show that adoption of these set phrases by American English is becoming more and more common. It seems that the reasons for the integration of Chinese wisdom into American verbal culture lie in strengthening of China position on international scene as well as expansion of diplomatic contacts and ties. In this paper we address the question of what actually governs the ways of naturalization of Chinese sayings and proverbs in the American English.

Keywords: Chinese Proverbs; American Verbal Culture; Paremia; Intercultural Communication; Worldview

\section{Introduction}

The end of the $20^{\text {th }}$ and the beginning of the $21^{\text {st }}$ century can be defined as the period of increased cross-cultural contacts and communication, which inevitably result in interaction and interpenetration of languages and cultures of contacting countries. Modern era of globalization and integration creates new conditions for these processes to become even more pervasive and comprehensive. Unprecedented scale of intercultural communication due to global migration, mass media, and ubiquitous access to the World Wide Web make entirely distant societies come into contact and let them take over nuggets of culture-loaded information and wisdom.

One of the crucial aspects of intercultural communication is language contacts which habitually accompany culture interactions. Despite significant research made in the field of language contacts, especially loanword phenomena, there are still apparently few works devoted to proverb borrowings. However, the evidence proves that foreign language proverbs freely and extensively circulate in many world languages. In this regard contemporary English, where their frequency as well as diversity has recently become remarkably conspicuous, deserves a special study. Numerous proverbs of other countries are not only quoted in the English-language communication, but also enter proverb corpora and dictionaries of English.

It holds particularly true for the phenomenon of Chinese proverbs. The empirical data shows that adoption of these set expressions by American English is becoming more and more common. Yet, almost no research has still been made in attempt to address the question of what actually governs the ways of naturalization of Chinese sayings and proverbs in the English language of the USA.

With this in mind we aim at analyzing Chinese proverbs and sayings quoted in American verbal communication, mass and social media in particular. Thus, the objective of the study is to analyze particular types of transformation that Chinese proverbs and sayings undergo in the process of entering the American verbal culture. We proceed on the assumption that paroemias are the vehicles of cultural values and intend to investigate Chinese proverbs in American discourse by revealing the ways of Western and Asian worldview interactions.

This is a specific aspect of a much broader issue of intercultural communication, that is how proverbs being both 
verbally and culturally unique enter entirely different society and eventually become the part of its verbal culture and communication. W. Mieder (2010) rightly noticed that "with oral, written, and visual mass media and tourism, economics, and politics helping to spread these proverbs and proverbial phrases, paremiologists need to pay much more attention to the multifaceted roads of this phenomenon that augments global communication." (p.43).

\section{Area Descriptions}

\subsection{Proverb Definition and Chinese Proverb Distinction}

Most studies concerned with the phenomenon of a proverb normally begin with its definition. However, despite significant job made in this field, there is still no mutual consent among scholars on its essence. Among the main reasons for this difficulty are a long history of multispectral investigation of a proverb and the complexity of the phenomenon itself.

People have been using and collecting proverbs since ancient times, with the earliest proverb collections known stemming from the third millennium B.C. (Mieder, 2004, p. xii). It gave rise to studying various aspects of proverb functioning, which also has a long history dating back to the times of Aristotle and Plato. It is no wonder that so many efforts of trying to take a look deep into the essence of this phenomenon generated different approaches to defining it, which range from religious view to cognitive one (see Honeck, 1997, pp. 5-44).

Ambiguity in the definition can also be explained due to the complex nature of proverbs as they present both "linguistic items (possessing concrete elements of verbal and logical structure) and behaviors (possessing motives, strategies, and outcomes)" (Kimberly, Tokofsky, \& Winick, 2004, p.2).

Traditional proverb definition describes them as fixed, pithy, self-contained expressions, which have didactic meaning and possess some poetic features (Norrick, 1985). There are also numerous definitions that refer to their structure, pragmatic functions in communication and genre. In such a variety of approaches and views one cannot but agree with Matthew S. Kaplan (2002), who mentioned that "the condensed nature of proverbs allows them to be interpreted again and again, across time and in different situations" (para.1). Such a complexity becomes a reason why some researchers would rather give characteristic features of a proverb than try to find an all-embracing definition. (Nikolaeva, \& Yakovleva, 2015).

Chinese sayings and proverbs are entirely different from others not only in structure, but also in values and attitudes they are associated with. For one thing, Chinese proverbs do not fit completely into the accepted Western classification of set expressions and proverbial subgenres. As Arthur Henderson Smith (2013) rightly observed in his book first published in 1902, "the Chinese themselves do not recognize a distinct class of expressions corresponding to what in English we designate as proverbs". (p.4). Chinese set expressions are generally classified according to their compositional features into several groups: yànyǔ (谚语 - complete sentences, which have didactic meaning and express a judgment), súyǔ (俗语 - colloquial set phrases), chéngyǔ (成语 - idioms that have four-character structure), xiēhòuyǔ (歇后语 - truncated allegorical sayings), géyán (格言 - maxims taken from well-known writings), jǐngjù (警句 - aphorisms), guànyòngyǔ (惯用语 - idioms, which meaning cannot be deduced from the sum of their constituent parts).

All the listed categories present the sources of what is quoted in American verbal communication as a "Chinese proverb / saying".

The other thing that makes Chinese proverbs distinct is, as in Lauhakangas (2014) "a more important quality which seems apparent in Chinese proverb texts: virtue or morality." (p. 55). Chinese proverbs are in fact associated with the notions of moral values, wisdom and ethics resulting from the history of five thousand years of evolution during which Chinese civilization accumulated numerous pearls of life experience.

Proverbs and set expressions can be found in almost every language as they present universal tool for engraving folk experience and passing it from one generation to the other. However, identifying the place proverbs have in Chinese life and their role in society, it is important to mention that "in no country does the proverb flourish more abundantly than in China" (Hart, 1937, p. XIX). Anyone, who deals with Chinese people or society soon "becomes aware of the allpervading nature of proverbs and proverbial sayings in Chinese life, both in daily speech, as well as in Chinese writings and other media" (Rohsenow, 2003, p. xi).

China presents one of the most ancient cultures in the world, which begot hundreds of proverbs and sayings that encapsulate folk wisdom and experience corresponding to almost every domain of life. Yet, contemporary linguistics still evidences the lack of profound theoretical researches in the field of Chinese paremiology, as well as studying the processes of the dissemination of these proverbs across the globe, which in modern times is gaining more popularity. 
Chinese proverbs have been classified and categorized for a long time, resulting in compiling many dictionaries of Chinese proverbs and sayings, but there certainly exists a need for investigating the very essence of this phenomenon and its unique features.

\subsection{Proverbs as the Vehicles of Cultural Values}

Proverbs serve as the great source for a throughout insight into a culture and values that constitute its core. Numerous studies conducted on the basis of set phrases proved their reliability as the material to reveal cultural traditions, beliefs and assumptions.

Being culture-loaded language units, which in condensed form transmit the experience of previous generations, proverbs and sayings communicate the information about the way how people perceive the world around them. If any aspect of life experience is of importance for a culture, it will be reflected and encapsulated in a group of proverbs with the same meaning.

For instance, time orientation is expressed in numerous proverbs found in every language. Thus, K. Lau (1996) in her research based on 10 most frequent proverbs in American mass media found out that time takes the leading place in American culture and ideology. Value of time for American culture is in fact reflected in many proverbs that warn against wasting and losing it: Time wasted is time lost; Lost time is never found; Time passes quickly, make good use of it ; Don't fiddle your time away; An hour wasted can never be regained, etc.

Proverbs with the same meaning can be found in almost every language since this category is universal across the globe and people generally recognize the value of time (Compare: Chinese 濑惰一时损失一生 - (lit) be lazy for one time and you will lose for your whole life. (fig) do not waste time idly; Russian Потерянного времени не воротишь [Poteryannogo vremeni ne vorotish] - lost time is never found again).

However, a closer look at proverbial discourse of a given language can reveal unique perception of time typical for the culture. Thus, Chinese culture according to Kluckhohn and Strodtbeck taxonomy is characterized as past-oriented, whereas American culture is viewed as the future-oriented one (Samovar et al, 2010; Li, 2008). According to Chan \& Rossiter (1998) "the strong past-time orientation of the Chinese is well-documented in the literature" (p.64). Numerous Chinese proverbs like 温故知新 (learn the new by restudying the old), 人不可忘本 (one should not forget one's roots), 前事不忘后事之师 (past experience, if not forgotten, is a guide for the future) in fact display orientation of Chinese culture to the past. This, of course, is not to say that Chinese language contains set expressions that highlight orientation of the culture to the past only. One undoubtedly can find Chinese expressions like 未雨绸缪 (repair the house before it rains); 长江后浪推前浪 (in the Changjiang River the waves behind drive on those before), etc., which show orientation to the future. However, vast number of traditional proverbs contain advice on valuing the past, which in turn will help gain better future - 惩前毖后 (Learn from past mistakes to avoid future ones).

American proverbs confirm just the contrary: Many people will forget the past for a present ; Planning your future saves you from regretting your past ; You can never plan the future by the past ; Live well in the present; the past is gone forever; Keep your eyes on the future, never on the past ; Let bygones be bygones, etc.

Though the English language contains some proverbs that stress the importance of the past (e.g. Study the past if you would divine the future) or present events (e.g. Present neglect makes future regret), they totally constitute a relatively small figure. The saying "It's the future that counts" undoubtedly becomes a guiding line for American culture. One cannot but agree here with L. Samovar's (2010) statement that "this does not mean that Americans have no regard for the past or no thought of the present, but it is certainly true that most Americans, in thought or action, tend to look forward". (p. 213).

Hence, quantitative analysis of groups of proverbs belonging to different languages as well as the comparison of proverbial meanings may disclose unique perception of value dimensions, typical of a given culture. In this study we proceed on the assumption that proverbs contain information about cultural traditions, beliefs and values, they present people's worldview and reflect collective cognition.

\section{Methods}

\subsection{Material Studied}

The study was conducted on mass and social media material, which is mainly represented by online versions of such quality press as The New York Times, The New York Daily News, Los Angeles Times, etc. as well as commentaries, blog 
post, forum notes, etc. The choice of material is determined by the assumption that media texts serve as an effective resource for the description of contemporary language since all the changes, happening with it, are immediately reflected in this kind of discourse. Online versions of newspapers are now gaining more popularity, and are becoming one of the major sources of disseminating information. Statistics show that "the digital audience engaged with newspaper content reached a new peak in March 2015, totaling 176 million adult unique visitors. The count is a 10\% increase from the 161 million unique visitors measured by comScore in March 2014" (http://www.naa.org/trends-and-numbers/newspaperwebsites/newspaper-web-audience.aspx).

This way of communication presents new conditions for interpenetration of languages and cultures since it erases distance and time limitations. Mass media creates great opportunities for studying processes that take place in modern society.

\subsection{Techniques and Procedure}

In the first stage of the study we collected those fragments of discourse that contained Chinese set expressions with or without allusion to their origin, resulting in total number of 315 cases with 50 different proverbs found.

The next step was to trace and examine the transformations that Chinese proverbs and sayings undergo in an entirely different environment of American communication. That was done by comparing meaning, imagery, and formal structure of original Chinese proverbs with those quoted in American discourse.

After that we tried to see whether and how belief systems of two cultures correspond, and investigate the ways of how American and Chinese worldview interactions affect naturalization of a Chinese proverb in American verbal culture. For this purpose we applied content discourse analysis revealing broad contextual environment of a Chinese proverb in American discourse indicative of actualized cultural concepts and values.

While selecting the material we made a distinction as to author's ethnicity, where it was possible, since we proceeded on the assumption that the usage of Chinese paroemias by American English native speakers only can be indicative for the process of true and stable incorporation of Chinese sayings, proverbs, or aphorisms into American verbal communication.

\section{Results and Discussion}

The data analysis revealed that in American verbal communication Chinese proverbs were used in wide range of contexts, which varied from China-related topics to non-Chinese themes. The comparison with our previous study (Yakovleva \& Nikolaeva, 2014) indicated discrepancy regarding the percentage in using proverbs in non-Chinese topics. More empirical data showed the predominance of that type of context, which comprised $59 \%$ of all analyzed examples, that was indicative for the processes of stable integration of Chinese proverbs into American verbal culture.

The research provided evidence that the adoption of Chinese proverbs and their current use in the American verbal culture was generally connected with the transformation of original phrase according to the following types: a) transformation of image component, and b) transformation of message component. It should be noted that in conducting the research we followed Matti Kuusi's structural model of a proverb, which proposed three components of its structure: proverb image, proverb message and proverb architectural formula (as cited in Dundes, 1994, p.46). By proverb image we meant particular lexical units that formed its figurativeness. Proverb message was the meaning of a proverb, whereas architectural formula referred to its composition. Due to the difference in language structures architectural formula of Chinese proverbs was transformed in all cases.

Chinese proverbs entering American communication revealed Western and Asian worldview interaction which yielded multiple results depending on active or neutral roles Chinese and American worldviews played in relation to each other in a concrete discourse fragment. The examples proved that either Chinese or American values alternately took the leadership in American discourse, which was also conditioned by the topic, whether it was or was not related to China.

In most cases Chinese worldview was neutral in the recipient American culture, which brought about profound transformation of Chinese proverbs, involving image or/and message component. Such examples constituted the majority due to the difference in belief systems of interacting societies.

In much fewer cases, particularly in China-related discourse, the Chinese worldview was more active. In nonChina-related discourse the active role of Chinese values resulted in introducing new cultural models by Chinese proverbs into the recipient American worldview.

There were some examples though where there was a parity of roles between Chinese and American worldviews, leading to the combination of a Chinese proverb with an American match in one statement. 
Let us consider these results in detail.

\title{
4.1 Transformation of Image Component
}

Transformation of image component implies manipulations with the original proverb image. As it presents a complex phenomenon, it may be of various types. One of them was the replacement of the original proverb image by a more familiar (to a receiving culture) one. In other cases the lack of a familiar and recognizable image led to original image ellipsis.

The obtained data showed that first and foremost subjects to image modulation were proper names, geographic names, units of measure, etc. Thus, one of the most frequent proverbs found in American mass and social media discourse 千里之行, 始於足下 (lit. a journey of a thousand li's begins from under one's foot) displayed multiple variants of the phrase translation: the longest journey, every journey, any great journey, the journey of a thousand miles, etc. The examples provided evidence that Chinese unit of measure li being not customary for American culture was completely omitted or substituted for a more habitual mile, as in the fragment below:

\begin{abstract}
Mr. Kerry's announcement of the pact between China and the United States was rightly described as "historic." Both sides agreed to agree, rather than to disagree. The Chinese proverb "a journey of a thousand miles begins with a single step" is most appropriate. Agreeing to agree is the first step in this thousand-mile journey that we all face together and that we cannot make alone. (McCullough, 2014).
\end{abstract}

The metaphor of thousand-mile journey was extended beyond the proverb itself. Such examples reflect creative processing of borrowed material by the receiving culture.

The excerpt below devoted to economic cooperation between the USA and China, revealed transformation of a Chinese proper name image in American discourse. The US Secretary of Health and Human Services Michael Leavitt referred to the Chinese idiom 愚公移山 with literal translation “Yu Gong moves mountains" in the following way:

Leavitt, who will sign an agreement Tuesday on food and feed product safety, and a second on drugs and medical devices, quoted a Chinese proverb in saying the bridge-building would take time. "The man who removes a mountain begins by carrying away small stones," he said. (Stillwell, 2007).

As seen from the example above, the idiom image was transformed, the proper name was reduced. The proverb form presented the cognitive model of a parable - its meaningful core and allusion to ancient Chinese parables. The story behind the proverb, which is about an old man who once decided to clear away two mountains that blocked a passage to a city and eventually did it stone by stone, was most probably lost for the non-Chinese audience.

We also came across this proverb used in non-Chinese topics, as in the following example:

So just how do you move a mountain then? Well, this brings us to an ancient Chinese proverb: "The man who moved a mountain was the one who began carrying away small stones." The trick with very ambitious goals like losing weight or making lots of money is to take things in small steps slowly but on a regular basis, much like carrying away those small stones a bit at a time. (Cora, n.d.).

Interestingly enough, that the similar cognitive ways of life experience are conspicuous in quite a number of English-language proverbs Little by little the bird builds his nest, Drop by drop and the pitcher is full, A steady drop makes a hole in a rock, The falling drops at last will wear the stone, Patience and time conquer all things (Mieder, 1996) which convey the same meaning - "persistence and perseverance help achieve results".

However, Chinese proverbs have gained great popularity in American communication due to the presumed unquestionable wisdom and hence stronger persuasion capacity, even if the original Chinese images are lost for American public at large. In all the above cases of discourse the American worldview dominated over the Chinese one adjusting proverbs to its texture or quality.

\subsection{Transformation of message component}

Transformation of message component implies semantic shift in cognitive basis of the initial saying. Metaphorical structure of borrowed Chinese proverbs sometimes leads to new interpretation of proverb meaning, thus resulting in association with different values in new cultural environment.

This way, one of the examples revealed the emergence of new interpretation pattern of the original Chinese counterpart: 
"IF YOU want one year of prosperity, grow grain. If you want ten years of prosperity, grow trees. If you want 100 years of prosperity, grow people." This old Chinese proverb crudely sums up how the entry of China's massive labour force into the global economy may prove to be the most profound change for 50, and perhaps even for 100, years ("How China runs the world economy," 2005).

The author of the article referred to the Chinese proverb 十年树木百年树人 with literal translation "it takes ten years to grow trees, but a hundred years to rear people" (fig. a good education program takes a long time to develop).

While ancient Chinese proverb highlights the idea of time-consuming and laborious process of upbringing a new talented generation, thus displaying emphasis on moral values, in a new environment the proverb demonstrated the shift towards materialistic and economic values. Being a consumer society, the USA displays a higher degree of materialism than China. Some researchers include materialism into the list of core American values (Kohls,1984, Althen, 2003, Samovar, 2010 etc.). This can be possible explanation why Chinese proverbs sometimes undergo the changes of value components and acquire new value associations, thus changing the message.

The same holds true for the proverb 授人以鱼不如授人以渔 with literal translation "give a man a fish and you feed him for a day; teach a man to fish and you feed him for a lifetime" and figurative meaning "knowledge is the best charity", which was used in the following context:

Original Chinese Proverb: Give a man a fish and he will eat for a day. Teach a man to fish and he will eat for a lifetime. 2012 White House Revision: Give a man a welfare check, a free cell phone with unlimited free minutes, cash for his clunker, Food stamps, section 8 housing, free contraceptives, Medicaid, ninety-nine weeks of unemployment, Free meds, and he will vote Democratic the rest of his life; even after he's deceased" (Jackson, 2012).

Sometimes one original Chinese proverb has two entirely different meanings in American discourse. Let us compare two examples:

1. "It takes two hands to clap and similarly, it takes two sides to build a relationship," adds Devesh Kapur, director of the Center for the Advanced Study of India and professor of political science at the University of Pennsylvania. "Both were willing to look ahead rather than be weighed down by the past. But underlying the pragmatism are the large structural changes taking place in Asia, especially the rise of China and the attendant geopolitical uncertainties." ("What was it worth? Assessing the value of Obama's India visit", 2015)

2. You need psychiatric help for guys like Artest, Sprewell, Rasheed, Rodman. It doesn't matter who started it; anytime ANYONE argues back, they are just as much to blame. It takes two hands to clap (Chinese proverb that doesn't really make sense, but basically means that the whole "he started it" justification is for elementary school kids) (Miller4ever, 2009).

The comparison of these examples revealed that the proverb "It takes two hands to clap" had entirely different meaning in various contexts. It broaches the issue of semantic ambiguity or semantic indefiniteness of proverbs problem, which is still disputable in modern paremiology. Proverbs, as W. Mieder puts it, "are usually employed to disambiguate complex situations and events. Yet they are paradoxically inherently ambiguous, because their meaning depends on analogy" (Mieder, 2014, p.28).

The ambiguity in some proverbs becomes characteristic due to their metaphorical nature. Above mentioned proverb in fact fits the group of metaphorical proverbs that are employed in discourse in their figurative meaning. However, it does not seem to be the case in these particular examples as there are several proverbs in Chinese with the same literal English translation "it takes two hands to clap", but different figurative meanings:

孤掌难鸣 'It's difficult to achieve anything without support';

一个巴掌拍不响 'It takes two to make a quarrel';

一手独拍，虽疾无声 (refers to narrowness of governor's merits, e.g. power without talent or vice versa).

Thus, the ambiguous nature of the proverb found in American discourse can be explained as the result of different Chinese source-proverbs it refers to.

Just as it was the case with the transformation of the image component the modulation of the proverb message signifies that Chinese proverbs function in American discourse as an effective tool in the hands of a new creative master. The dominant character of American worldview in American discourse is dictating its rules to foreign proverbs communicative behavior transforming the conveyed image, message or value. 


\subsection{Emergence of New Cultural Patterns}

Most contemporary cultures undergo considerable changes due to globalization and integration as well as extensive intercultural contacts. This makes possible for Chinese values in some particular cases (though not numerous) to take over the leading role in American discourse. Hence, new cultural patterns may arise among the outcomes of Chinese and American worldview interactions.

Applying G. Hofstede's cultural dimensions theory and the 6-D Model, China scores 20 on individualism dimension and thus can be characterized as a highly collectivist country (average score for Asian countries - 24, world average 43) (http://geert-hofstede.com/china.html). It is widely known that one distinctive feature of collectivist societies is the predominance of group interests over personal ones. As it was mentioned before, proverbs transmit information about cultural values, beliefs and assumptions. If any of life domains is of importance for a society, then it would be highlighted in a number of proverbs with the same meaning. This way, Chinese paremiological fund contains numerous proverbs that warn against trying to stand out: 树大招风 - high trees attract the wind (fig. a person in a high position is liable to be attacked); 枪打出头鸟 - the shot hits the bird that pokes its head out (fig. the outstanding usually bear the brunt of attack); 出头的椽子先烂 - prominent rafter is the first to rot (fig. he who loves to be in the public eye, ends up badly); 人怕出名猪怕壮 - a man dreads fame as a pig dreads being fat (fig. fame can be dangerous).

American culture, on the contrary, at a score of 91 on the dimension is characterized as highly individualist society (http://geert-hofstede.com/united-states.html). This means that the society ranks highly such qualities as individuality, eccentricity, and originality. Being the country of emigrants, USA is one of the most multinational countries in the world that recognizes and protects every individual's right to be different from others. Self-reliance and self-trust are highly valued in individualistic cultures. Proverbial lore serves as a great reflection of it: the squeaky wheel gets the grease; he who begs timidly, courts refusal; shy children get no sweets, etc. All these proverbs convey the same idea - attracting a lot of attention will help get desirable things.

At the same time, culture is not rigid and fixed entity. It is dynamic and reflects any changes that are taking place in society. The result of these processes is the emergence of new cultural patterns. For example, in the US verbal communication, where the phrase «if you want something done right, do it yourself» serves as leading guide for behavior, Chinese proverb 众人拾柴火焰高 (lit. more firewood makes a bigger fire) is gaining popularity:

"ONLY when all contribute their firewood can they build up a strong fire," says a Chinese proverb. With the world economy in its worst crisis in 70 years, every country needs to do its bit to rekindle global demand. The American government, which plans to run a budget deficit of $12 \%$ of GDP this year, has called on its Group of 20 partners to do more ("Got a light?", 2009).

Probably, in American worldview team spirit should be fostered, while in China collectivism is natural and inborn, and hence a lot of Chinese proverbs convey it as a cultural value. In the example above we saw almost no changes of imagery or message of the proverb. Instead, we observed dominance of the Chinese worldview exerting its influence on American assumptions. The value of collective efforts imprinted in the Chinese proverb was introduced as the universal unquestionable truth, and a challenge for the course of urgent actions.

However, it should be noted that such cases of borrowed proverbs usage are not systematic. Proverbs of that kind were rather used in China-related topics. Despite the fact that such proverbs have not been fully assimilated by American culture, it was possible to trace an encroaching delicate trend in the American worldview.

\subsection{Combination of Chinese Proverbs and American Set Expressions}

Besides the above mentioned cases, the processes of Chinese proverbs integration and worldview interaction can be shown on the examples, where Chinese set phrases were followed by American or European proverbs. Similarity of values, views on reality, and basic assumptions encapsulated in proverbs lead to cases, where proverbs belonging to different cultures presented a close match and in communication reciprocally duplicated each other's meaning amplifying the pragmatic effect.

The example below contained Chinese proverb 妇女能顶半边天 (lit. women hold up half the sky; fig. nowadays, women have an equal part to play in society), which was intensified by American maxim "United we stand, divided we fall":

Nicholas D. Kristof, NY Times journalist and his wife, Sheryl WuDunn, former NY Times journalist and editor, portray in 
their new nonfiction book, Half the Sky, how, if given the opportunity, women can shine even in the darkest corners of life. The title is part of an ancient Chinese proverb: Women hold up half the sky. I'm guessing the other half lies on the shoulders of men. When either side falls, it's harder for those who are still standing. Just like the 13 colonies - 'United we stand, divided we fall' (Matsveyenka, 2010).

Determined by the author's pragmatic intention, the use of two proverbs belonging to different cultures disclosed their harmonious combination in one statement. The Chinese values didn't just echo the American ones, but both resonated with each other. Chinese imagery of the proverb, though not fully grasped by the non-Chinese audience, was nevertheless quite clear and comprehensible.

In other cases more familiar European or American equivalents duplicated the meaning of a Chinese proverb to help better understand its figurative meaning:

The longest journey begins with a single step" is a saying that originates from a Chinese proverb and is also the very beautiful lesson I learned this week. <...> I think we all at some point need to be reminded that Rome wasn't built in a day". (Yaw, 2014).

Another close match of Chinese and American proverbs (and hence values) was found in the following example: 'THE Chinese have a saying, 'Fu bu guo san dai,' or 'Wealth never survives three generations.' America has its own version of this saying: 'From shirtsleeves to shirtsleeves in three generations.' As with most old proverbs, there is a grain of truth to this-and the new rich are searching for ways to avoid history's curse" ("To have and to hold,"2001).

Reinforcement of the Chinese proverb 富无三代享 with an American one demonstrated the parity roles of both worldviews in that particular communication act. Similar values, the same "view on things" is another strong cause for foreign language proverb borrowing. People eagerly quote foreign proverbs which in combination with their native ones augment and facilitate the impression of the world universal truth and help persuade the audience.

\section{Conclusion}

It seems that the reasons for the integration of Chinese wisdom into American verbal culture lie in strengthening of China position on international scene as well as expansion of diplomatic contacts and ties. Mass media plays special role in these processes because globalization of information flow promotes interpenetration of languages and cultures. At the same time, mass media texts are becoming quite reliable source for studying all the processes that are happening with language since all the changes are immediately reflected in them.

American verbal culture of contemporary mass and social media presents the area, where proverbs and sayings that belong to different cultures intertwine and interlace with each other, thus causing interaction of worldviews. Such an interaction can be clearly seen on the examples, where foreign proverbs undergo modulation of their imagery, message or value components, which happens as the result of difference in value systems or life realities that surround people.

The investigated material proved that Chinese proverbs being perceived by Americans as pearls of wisdom of an ancient civilization are eagerly quoted in mass media to augment the impression of the world universal truth and help persuade the audience. Chinese proverbs function in American discourse as an effective tool in the hands of a new creative master.

Distinguished from just a quotation a proverb borrowing is a much more profound phenomenon, which happens in case when both cultures share common values and the ways of perceiving the reality. Bright, vivid, and easy to grasp imagery of Chinese paroemias is another cause for proverb borrowing. As a result, Chinese proverb in due time becomes a part of American proverbial lore.

\section{References}

Althen, G. (2003). American ways: A guide for foreigners in the United States. USA: Intercultural Press.

Cora, C. (n.d.). How to move a mountain. [Blog post] Retrieved from: http://www.lifehack.org/articles/productivity/how-to-move-amountain.html.

Chan A.M.\& Rossiter J.R. Construction of a Chineseness Values Scale and a Chineseness Ethnicity Scale. AP - Asia Pacific Advances in Consumer Research, 3, 61-67.

Dundes, A. (1994). On the structure of the proverb. In Mieder, W \& Dundes, A. (Eds.), The wisdom of many: Essays on the proverb (pp. 43-64). London: The University of Wisconsin Press.

Got a light? (2009, March 12). The Economist. Retrieved from: http://www.economist.com/node/13278758

Hart, H.H. (1937). 700 Chinese proverbs. Stanford: Stanford University Press. 
Honeck, R. P (1997). A proverb in mind: The cognitive science of proverbial wit and wisdom. London: Lawrence Erlbaum Associates Publishers.

How China runs the world economy (2005, July 28). The Economist. Retrieved from: http://www.economist.com/node/4223552

Jackson, D. (2012, September 24). New Obama ad hits Romney on 47\%. USA Today. Retrieved from: http://content.usatoday.com/ communities/theoval/post/2012/09/24/new-obama-ad-hits-romney-on-47/70000981/1\#.VbLnr57tmkp

Kaplan, M.S. (2002). Using proverbs to explore intergenerational relations across cultures. New York: University Press of America, Inc.

Kimberly, J. L., Tokofsky, P., \& Winick, S.D. (2004). What goes around comes around: The circulation of proverbs in contemporary life. Logan: Utah State University Press.

Kohls, L.R. (1984). The values Americans live by. Washington, DC: Meridian House International.

Lau, K. (1996). It's about time: The ten proverbs most frequently used in newspapers and their relation to American values. Proverbium: Annual Yearbook of Proverb Scholarship, 13, 135-159.

Lauhakangas, O. (2014). Categorization of proverbs. In Hrisztova-Gotthardt, H., \& Aleksa, M. V. (Eds.), Introduction to paremiology : A comprehensive guide to proverb studies (pp.49-66). Warsaw: De Gruyter Open Ltd.

$\mathrm{Li}, \mathrm{M}$. (2008). The unique values of Chinese traditional cultural time orientation: In comparison with Western cultural time orientation. Intercultural Communication Studies, 17, 64-70.

Matsveyenka, A. (2010, December 2). Journalists reveal horrors of treatment of women. New York Daily News. Retrieved from: http://www.nydailynews.com/new-york/journalists-reveal-horrors-treatment-women-article-1.470837

McCullough, P. (2014, November 12). An agreement on climate change. The New York Times. Retrieved from: http://www.nytimes.com/ 2014/11/14/opinion/an-agreement-on-climate-change.html?_r=0

Mieder, W. (1996). A Dictionary of American Proverbs. New York: Oxford University Press.

Mieder, W. (2004). Proverbs. A handbook. Westport: Greenwood Publishing Group.

Mieder, W. (2010). Many roads lead to globalization. The translation and distribution of Anglo-American proverbs in Europe. In J. Korhonen, W. Mieder, E. Piirainen \& R. Piñel (Eds.), Phraseologie global - areal - regional (pp. 43-59). Tubingen: Gunter Narr.

Mieder, W. (2014). Behold the proverbs of a people. USA: University Press of Mississippi.

Miller4ever (2009, March 21). Re: Jarrett Jack vs T.J. Ford. [Blog comment]. Retrieved from: http://forums.realgm.com/boards/ viewtopic.php?t=891847al

Nikolaeva, O.V. \& Yakovleva, E.A. (2015). The pragmatics of Chinese proverb quoting in the English and the Russian-language mass media of PRC. Asian Social Science, 11, 211-220. doi: 10.5539/ass.v11n15p211.

Norrick, N. R. (1985). How proverbs mean: Semantic studies in English proverbs. Berlin: Mouton.

Rohsenow, J.S. (2003). ABC dictionary of Chinese proverbs (Yanyu). USA: University of Hawaii Press.

Samovar, L., Porter, R., \& McDaniel, E. (2010). Communication between cultures. USA: Wadsworth

Smith, A. H. (2013). Proverbs and common sayings from the Chinese. London: Forgotten Books. (Original work published 1914).

Stillwell, J. (2007). U.S., Chinese officials: We must fight protectionist sentiment. USA Today. Retrieved from: http://usatoday30. usatoday.com/news/world/2007-12-10-uschina-trade_N.htm

To have and to hold (2001, June 14). The Economist. Retrieved from: http://www.economist.com/node/654077

What Was It Worth? Assessing the Value of Obama's India Visit (2015, February 2). Retrieved from: http://knowledge.wharton.upenn. edu/article/worth-assessing-value-obamas-india-visit/

Yakovleva, E.A. \& Nikolaeva, O.V. (2014). Chinese paroemias as intertextual insertions in American mass media and social media discourse. Intercultural Communication Studies, 13, 146-164.

Yaw, M.V. (2014, August 16). The longest journey begins with a single step. [Blog post] Retrieved from: http://mvyaw.blogspot.com/ 2014/08/the-longest-journey-begins-with-single.html 